\title{
REVIEW \\ Potential role of oxidative stress on the prescription of rehabilitation interventions in spinal cord injury
}

\author{
T Lam $^{1,2}$, Z Chen $^{1,2}$, MM Sayed-Ahmed ${ }^{3}$, A Krassioukov $^{2,4,5}$ and AA Al-Yahya ${ }^{3}$
}

\begin{abstract}
Study design: Review article.
Objectives: To provide an overview of free radical biology, particularly with respect to muscle physiology, as well as the potential effects of muscle morphological changes, physical capacity and nutritional status on oxidative stress in people with chronic spinal cord injury (SCl). The potential implications of these factors for determining the optimal dosage of rehabilitation training interventions in people with chronic SCI will also be presented.
\end{abstract}

Setting: Vancouver, BC, Canada.

Methods: Literature review.

Results: Not applicable.

Conclusion: There has been a great deal of focus on rehabilitation exercise interventions providing intensive practice of movements to enhance functional recovery and physical capacity following SCl. However, there is still much to be understood about the appropriate dosage of training parameters (e.g. frequency, duration). It has been known for several decades that exercise increases free radical production, leading to oxidative stress. To date, there has been little consideration of the potential interaction of oxidative stress with training parameters on functional outcomes in chronic SCl. Furthermore, individuals with chronic SCl face many secondary consequences of their injury, such as muscle atrophy, change in muscle fiber type, general deconditioning and nutritional status, that are known to influence free radical production and antioxidant capacity. Better understanding of the potential confounding effects of oxidative stress associated with exercise will improve our ability to determine the optimal 'dose' of rehabilitation training to maximize functional recovery following $\mathrm{SCl}$.

Spinal Cord (2013) 51, 656-662; doi:10.1038/sc.2013.71; published online 16 July 2013

Keywords: oxidative stress; free radicals; exercise parameters; rehabilitation parameters; training intensity

\section{INTRODUCTION}

The worldwide incidence of spinal cord injury (SCI) is estimated to be between 10.4 and 83 per million inhabitants per year. ${ }^{1}$ Owing to significant deficits in mobility, sensation and cardiovascular regulation, people with SCI tend to have inactive lifestyles. ${ }^{2}$ Accordingly, one of the leading causes of morbidity and mortality among the chronic SCI population is cardiovascular disease and Type 2 diabetes. ${ }^{3}$ Furthermore, movement deficits have a significant impact on health, independence and social participation in people with SCI. ${ }^{4}$

Physical activity and exercise are important for optimizing mobility and reducing the sedentary lifestyles that lead to greater risk of secondary complications (e.g. osteoporosis, pressure ulcers, orthostatic hypotension) and chronic disease. ${ }^{5-7}$ Numerous studies have examined the functional and health outcomes of various rehabilitation interventions for people with SCI, ranging from seated arm cycling, body-weight-supported treadmill training (BWSTT), wheelchair ergometry and functional electrical stimulation leg cycling. ${ }^{8,9}$ However, there is still much to be understood for determining optimum training parameters (e.g. frequency, duration and progression of training) for this population. In the example of BWSTT, parameters of intensity and duration have been primarily derived from the hypotheses that greater volume of training (i.e. intensive and repetitive task-specific practice of walking) is required to enable neural adaptations underlying functional improvements, ${ }^{10}$ but there has been little consideration of secondary (and potentially deleterious) factors that could result from strenuous training.

There is evidence that exercise, especially when performed strenuously, is associated with the overproduction of free radicals (mainly reactive oxygen species) or reduced detoxification by antioxidant defense systems in able-bodied subjects, ${ }^{11}$ situations that could lead to oxidative stress. Oxidative stress is a condition where the toxic effects of free radicals are not adequately counteracted by the body's antioxidative defenses. In SCI, oxidative stress has usually been considered with respect to secondary damage after the acute injury and much attention has been given to developing effective acute therapeutic interventions to alleviate the oxidative stress. ${ }^{12}$ However, beyond the acute phase, we have little understanding of how oxidative

${ }^{1}$ School of Kinesiology, University of British Columbia, Vancouver, British Columbia, Canada; ${ }^{2}$ International Collaboration on Repair Discoveries, Blusson Spinal Cord Centre, University of British Columbia and Vancouver Coastal Health Research Institute, Vancouver, British Columbia, Canada; ${ }^{3}$ Department of Pharmacology, College of Pharmacy, King Saud University, Riyadh, Saudi Arabia; ${ }^{4}$ Division of Physical Medicine and Rehabilitation, Faculty of Medicine, University of British Columbia, Vancouver, British Columbia, Canada and ${ }^{5} \mathrm{GF}$ Strong Rehabilitation Centre, Vancouver, British Columbia, Canada

Correspondence: Dr T Lam, International Collaboration on Repair Discoveries, Blusson Spinal Cord Centre, University of British Columbia, 818 West 10 th Avenue, Vancouver, British Columbia, Canada V5Z $1 \mathrm{M} 9$

E-mail: tania.lam@ubc.ca

Received 7 December 2012; revised 28 May 2013; accepted 5 June 2013; published online 16 July 2013 
stress responses may impact exercise capacity, and therefore, the prescription of rehabilitation training parameters in people with SCI.

Oxidative stress can lead to muscle fatigue and compromise force production, thereby interfering with exercise performance. Indeed, with greater intensity and repetition of movements, such as that found in many exercise-based rehabilitation interventions, there is likelihood for higher levels of perceived exertion and decreased ability to perform sustained movement patterns appropriately, particularly in people with neurological injuries where fatigability and reduced exercise capacity are known issues. ${ }^{13,14}$ Furthermore, the susceptibility to oxidative stress is further exacerbated by changes in lifestyle (including nutritional and physical activity), changes in muscle fiber properties and muscle atrophy-issues that are of particular relevance for individuals with chronic SCI. ${ }^{15}$ Better understanding of the potential confounding effects of oxidative stress associated with exercise-based rehabilitation training will improve our ability to determine the optimal prescription of rehabilitation programs to maximize functional recovery following SCI (Figure 1). Thus, our objective here is to review the factors that could predispose individuals with chronic SCI to a greater risk of exercise-induced oxidative stress. We first provide a brief introduction and overview of oxidative stress and antioxidant biochemistry, particularly as it pertains to skeletal muscle physiology, followed by a discussion of the potential influence of these processes on the prescription of rehabilitation protocols in people with chronic SCI.

\section{BIOCHEMISTRY OF OXIDATIVE STRESS}

Free radicals: reactive oxygen species and reactive nitrogen species Free radicals are molecules with at least one unpaired electron, making them unstable and highly reactive with other molecules. Damage is caused when free radicals capture electrons from other molecules, including those found in DNA, lipids and proteins. The most significant types of free radicals in the human physiological system are those derived from oxygen or nitrogen.

Reactive oxygen species (ROS) include superoxide ion $\left(\mathrm{O}_{2}{ }^{-} \bullet\right)$ and hydroxyl radical $(\mathrm{OH} \bullet)$, and are produced as by-products of the normal metabolism of oxygen, such as that required for energy production in the mitochondria. Mitochondria have usually been considered to be the main source of $\mathrm{O}_{2}{ }^{-} \bullet$ in mammalian skeletal muscle. ${ }^{16}$ During oxidative phosphorylation, adenosine triphosphate
(ATP), the cell's main source of energy, is produced by the metabolism of energy substrates (that is, glucose, lipids) in the mitochondria. This process consists of a series of enzymatic reactions involving the reduction (electron acceptance) of oxygen. The reduction of an oxygen molecule by a single electron results in $\mathrm{O}_{2}{ }^{-} \bullet$, a free radical containing one unpaired electron. It is typically reported that $2-5 \%$ of the oxygen consumed by muscle mitochondria contributes to the production of ROS, ${ }^{17}$ although that number may be closer to $0.15 \%{ }^{18}$ Indeed, several other subcellular sources of $\mathrm{O}_{2}{ }^{-} \bullet$ in skeletal muscle have been identified, including that produced by the NADPH (nicotinamide adenine dinucleotide phosphate) oxidase enzyme found in the sarcoplasmic reticulum, transverse tubules and sarcolemma (reviewed in Powers and Jackson ${ }^{19,20}$ and Jackson). It appears that NADPH oxidase activity serves to generate $\mathrm{O}_{2}{ }^{-} \bullet$ (using NADPH as a substrate to transfer electrons to molecular oxygen) to influence calcium handling by the sarcoplasmic reticulum. ${ }^{21}$ As the level of NADPH oxidase activity is depolarization-dependent ${ }^{22}$ and as oxygen uptake will increase with contractile activity, $\mathrm{O}_{2}{ }^{-} \bullet$ levels could increase with exercise through this pathway. ${ }^{20}$

The availability of $\mathrm{O}_{2}{ }^{-}$- leads to several downstream reactions, resulting in the production of hydrogen peroxide $\left(\mathrm{H}_{2} \mathrm{O}_{2}\right)$ and $\mathrm{OH} \bullet$. Although $\mathrm{O}_{2}{ }^{-} \bullet$ is membrane impermeable, it has a relatively long half-life, allowing it time to oxidize (remove electrons from) protein constituents (mainly iron). $\mathrm{O}_{2}{ }^{-} \bullet$ can also dismutate (undergo simultaneous oxidation and reduction) into $\mathrm{H}_{2} \mathrm{O}_{2}$, a reaction that is catalyzed by superoxide dismutase ( $\mathrm{SOD}$ ). $\mathrm{H}_{2} \mathrm{O}_{2}$ is a stable, membrane-permeable molecule. Although it is not an ROS, it is considered a free radical because of its capacity to generate free radicals and produce resultant cytotoxic effects. In particular, $\mathrm{H}_{2} \mathrm{O}_{2}$ readily produces $\mathrm{OH} \bullet$, a highly reactive molecule and probably the most damaging of all the free radicals to cell components.

Reactive nitrogen species (RNS) are another common class of free radicals in biological systems, the most common being nitric oxide (NO). Like $\mathrm{O}_{2}{ }^{-} \bullet, \mathrm{NO} \bullet$ is highly reactive, forming other RNS, and its production is increased by contractile activity. ${ }^{19,23} \mathrm{NO}$ is converted from the amino-acid L-arginine by nitric oxide synthases (NOSs), whose activity is calcium-dependent. The primary action of $\mathrm{NO} \bullet$ is the production of cyclic guanosine monophosphate, but it is also the parent molecule of RNS, reacting with oxygen to form nitric dioxide

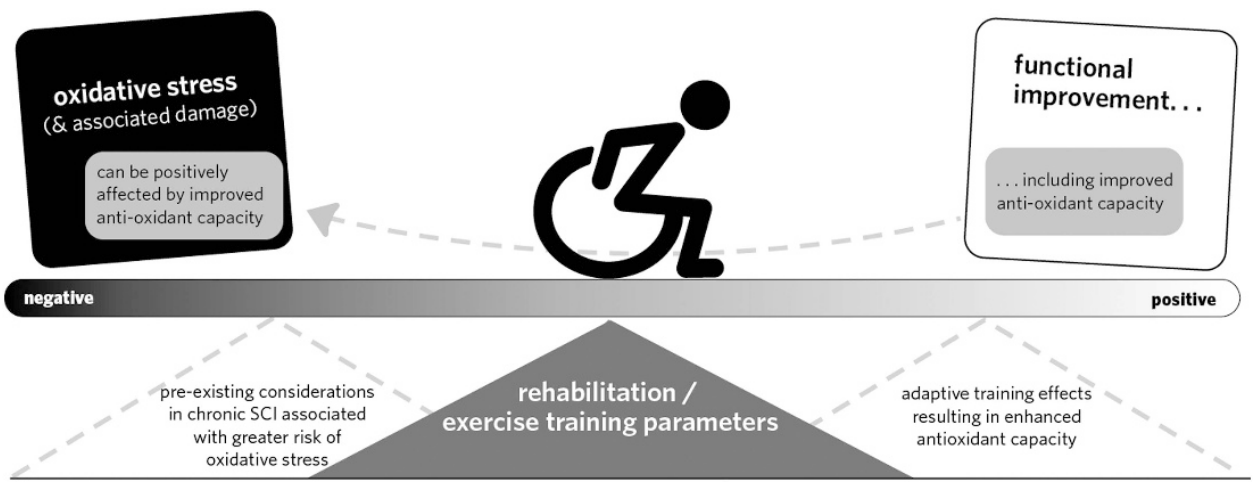

Figure 1 Oxidative stress and rehabilitation/exercise training parameters in SCI. In considering the appropriate dosage of rehabilitation or exercise training parameters, there should be a balance between the level of training intensity (i.e. frequency, duration) required to enable functional improvements and a level of training to minimize potential damage due to oxidative stress. Pre-existing considerations in people with chronic SCI, including muscle atrophy, muscle fiber type, general deconditioning and nutritional status, could necessitate greater consideration of the potential effect of intensive training parameters on the risk of damage secondary to oxidative stress (shifting this balance towards the left in the figure). On the other hand, positive adaptations with training over time could enhance antioxidant capacity, allowing for greater focus on training parameters that will improve function and less consideration for the potential negative side effects of training associated with oxidative stress (shifting this balance towards the right in the figure). 
$\left(\mathrm{NO}_{2} \bullet\right)$ and with $\mathrm{O}_{2}{ }^{-} \bullet$ to form peroxynitrite $\left(\mathrm{ONOO}^{-} \bullet\right)$, a strong oxidizing agent.

It is well documented that low concentrations of ROS and RNS are beneficial for a variety of tasks including stimulation of endogenous enzymatic and non-enzymatic antioxidant defense mechanisms and enhancing repair processes. ${ }^{24}$ Conversely, overproduction of free radicals overwhelms the antioxidant response, resulting in cytotoxicity through effects on proteins, lipids, carbohydrates and nucleic acids. Protein oxidation can involve cleavage of the polypeptide chain, modification of amino-acid side chains and conversion of the protein to derivatives that are highly sensitive to proteolysis, or directed degradation of proteins. ${ }^{25} \mathrm{OH} \bullet$ is known to react with the components of DNA, damaging both the purine and pyrimidine bases as well as the deoxyribose backbone by protein oxidation. ${ }^{26} \mathrm{OH} \bullet$ also initiates lipid peroxidation, resulting in the degradation of polyunsaturated lipids. As these lipids are the main constituents of cell membranes, consequences of lipid peroxidation include structural damage to the plasma membrane and impaired membrane protein function. ${ }^{27}$

\section{Antioxidant systems}

The regulation of ROS levels requires a precise balancing act between the normal by-products of metabolism, as described above, and the body's antioxidant systems. ${ }^{28}$ Antioxidants are defined as 'any substance that, when present at low concentrations compared with that of an oxidizable substrate, significantly delays or inhibits oxidation of that substrate. ${ }^{29}$ Antioxidants can exert their effects through a number of different mechanisms, including hydrogen atom transfer to break free radical-generating chain reactions, electron transfer to neutralize free radicals or catalyzing radical-scavenging reactions. $^{30}$ Endogenous antioxidants include ROS-specific antioxidant enzymes that are expressed constitutively in skeletal muscle: SOD, catalase and glutathione peroxidase (GPx). These enzymes work together to exert their antioxidant effects by catalyzing the downstream reactions of $\mathrm{O}_{2}{ }^{-} \bullet$, which is converted to $\mathrm{H}_{2} \mathrm{O}_{2}$ by SOD; conversion of $\mathrm{H}_{2} \mathrm{O}_{2}$ to water and oxygen or alcohol is then enabled by catalase or GPx, respectively. NO can also be considered an antioxidant as it is a very rapid scavenger of other free radicals (although in doing so, it will generate other downstream free radicals). ${ }^{31}$ Important non-enzyme antioxidants include vitamin E (especially $\alpha$-tocopherol), vitamin C, thiols (for example, glutathione, $\alpha$-lipoic acid) and flavonoids. ${ }^{30,32}$ Other compounds, such as free amino acids, peptides and proteins can also serve as ROS scavengers, but they are not strictly antioxidants as their scavenging effects are significant only at high concentrations. ${ }^{28}$

\section{Effects of free radicals on skeletal muscle function}

Both ROS and RNS have dual impact on muscle function, being both essential for normal force production on the one hand, and contributing to impairments in muscle force production on the other. In unfatigued skeletal muscle, low levels of free radicals found during basal conditions are, in fact, essential for normal force production. In experiments with isolated fiber bundles from rat diaphragm muscle, application of antioxidant enzymes against $\mathrm{H}_{2} \mathrm{O}_{2}$ or $\mathrm{O}_{2}{ }^{-} \bullet$ resulted in a reduction in muscle fiber twitch force and time to peak tension, ${ }^{33,34}$ but application of exogenous $\mathrm{H}_{2} \mathrm{O}_{2}$ at low concentrations $\left(<10^{-1} \mathrm{M}\right)$ resulted in an increase in these muscle fiber twitch parameters. ${ }^{33}$

$\mathrm{NO}$ and NOSs are also present in the skeletal muscle in low levels at rest and increase with muscle contraction. ${ }^{35-37}$ The effect of NO in unfatigued skeletal muscle has been shown to be inhibitory on force production. ${ }^{37,38}$ Application of an $\mathrm{NO}$ donor to isolated skeletal muscle fibers results in a reduction in maximal tetanic twitch force, whereas application of an NOS inhibitor has the opposite effect. ${ }^{37} \mathrm{NO}$ has also been proposed to exert its effect on force production through modulating a cyclic guanosine monophosphate pathway that inhibits skeletal muscle force, modulating calcium release from the sarcoplasmic reticulum or influencing cell membrane resting potential or actin-myosin interactions. ${ }^{38-40} \mathrm{NO}$ also has a powerful antioxidant effect against $\mathrm{O}_{2}{ }^{-} \bullet$ and it is possible that the negative effect of $\mathrm{NO}$ on muscle twitch force could be related to its buffering effect of ROS. ${ }^{39}$ Clearly, the interactions of ROS and NO during unfatiguing muscle contractions are intricate and complex, and the functional implications of their combined influence on skeletal muscle function is only beginning to be unravelled. ${ }^{41}$

When excess levels of ROS or RNS are produced, such as during strenuous exercise, deleterious effects on force production can result, leading to muscle fatigue. Many possible mechanisms have been proposed including alterations in calcium handling in the sarcoplasmic reticulum (both calcium release and re-uptake mechanisms), and changes in the structure and calcium sensitivity of myofilaments (for more detailed discussion of these mechanisms, see Powers and Jackson ${ }^{19}$ and $\operatorname{Reid}^{23}$ ). As a result, muscle fatigue can result from deficiencies in the regulation of sarcoplasmic calcium levels or impairments in the proper functioning of contractile proteins leading to impairments in force production.

\section{OXIDATIVE STRESS IN CHRONIC SCI}

Oxidative stress damage and antioxidant therapies in acute SCI have been extensively reviewed elsewhere (for example, see Jia et al. ${ }^{12}$ ), and will not be discussed here. Instead, we focus our attention on the potential impact of oxidative stress on the prescription of rehabilitation interventions for SCI beyond the immediate acute phase. Skeletal muscle atrophy, ${ }^{15}$ changes in muscle fiber type ${ }^{42}$ as well as general deconditioning and a sedentary lifestyle, ${ }^{43}$ commonly observed in people with SCI, are all factors that can influence exercise capacity as well as oxidative stress and antioxidant capacity. We propose that these issues should be considered by rehabilitation researchers seeking to advance our understanding of the optimal rehabilitation training parameters for individuals living with SCI (Figure 1).

\section{Changes in skeletal muscle after SCI}

Skeletal muscle atrophy. Muscle deconditioning is a common secondary consequence of SCI. The most visible effect of deconditioning is muscle atrophy, characterized by a reduction in size of individual muscle fibers (by as much as $45 \%{ }^{44}$ ) that is evident even 6 weeks postinjury. ${ }^{44,45}$ There is evidence that oxidative stress can promote skeletal muscle fiber atrophy, and also that in muscles that have been inactive, there is an accumulation of ROS. The earliest link between disuse-muscle atrophy and oxidative stress was illustrated by Kondo et al., ${ }^{46}$ who showed that that there were high levels of markers of muscle lipid peroxidation in muscles atrophied by immobilization. ${ }^{46}$ In humans, skeletal muscle atrophy induced by bed rest is also accompanied by increased protein carbonylation, a marker of oxidative stress. ${ }^{47}$ Numerous changes in mitochondrial morphology and biochemical function (including ROS production) are associated with the increased protein degradation and decreased protein synthesis that accompanies muscle atrophy. ${ }^{48}$ In addition, mitochondria-targeted antioxidants have been shown to have a protective effect against muscle weakness and atrophy in animal models of disuse muscle atrophy. ${ }^{49,50}$ Potential sources of oxidative 
stress in atrophied muscles include mitochondrial production of superoxide, $\mathrm{NO}$ produced by NOS, and $\mathrm{O}_{2}{ }^{-} \bullet, \mathrm{H}_{2} \mathrm{O}_{2}$ and $\mathrm{OH} \bullet$ as indicated by elevated sarcoplasmic levels of superoxide-producing xanthine oxidase, and iron (which is required for the conversion of $\mathrm{O}_{2}{ }^{-} \bullet$ and $\mathrm{H}_{2} \mathrm{O}_{2}$ into $\left.\mathrm{OH} \bullet\right)^{51-53}$ (Figure 2).

Skeletal muscle fiber type. Muscles below the level of the SCI also undergo dramatic changes in fiber phenotype. Numerous muscle biopsy studies have shown that most individuals within a few months postinjury have a significantly higher proportion of fast-twitch fibers in muscles below the level of the lesion, as indicated by staining for fast myofibrillar ATPase activity ${ }^{54,55}$ or higher proportion of muscle fibers with fast (Type IIx) isoform of the myosin heavy-chain protein and fast-fiber-specific isoform of the sarcoplasmic reticulum calciumATPase compared with able-bodied controls. ${ }^{56,57}$ The transformation toward predominantly fast-twitch muscle fibers is evident as early as 4-6 weeks postinjury, ${ }^{56,57}$ and as time postinjury lengthens, there is greater likelihood that all muscle fibers sampled will show complete transformation to Type II fibers. ${ }^{56}$

The changes in muscle fiber composition following SCI will contribute not only to fatigability but also have consequences for oxidative stress. Indeed, oxidative stress and antioxidant capacity are influenced by muscle fiber type. It has been shown in fast-twitch muscle fibers that the proportion of $\mathrm{H}_{2} \mathrm{O}_{2}$ production vs $\mathrm{O}_{2}$ consumed in the mitochondria is 2-3 times greater than that in slower-twitch muscle fibers. ${ }^{58}$ Also, neuronal NOS activity is strongly correlated with Type II fiber composition. ${ }^{38}$ Antioxidant capacity also varies with muscle fiber type. After an acute bout of exercise, GPx and catalase activity measured in rat skeletal muscles were significantly higher in soleus (predominantly Type I fibers) than in vastus lateralis (primarily Type II fibers). ${ }^{59}$ Furthermore, the increase in antioxidant enzyme activity (SOD and GPx) in skeletal muscle following intensive exercise has been shown to be greatest in Type I skeletal muscles but lowest in the fast-twitch muscles. ${ }^{60,61}$ Thus, in muscles that are completely or partially paralyzed by an SCI, changes in morphology and fiber type composition could lead to a predisposition towards greater oxidative stress and reduced antioxidative capacity. The propensity towards loss of Type I muscle fibers would further contribute to a decrement in antioxidative capacity.

\section{Effect of lifestyle changes after SCI}

Changes in nutritional status and especially changes in physical activity are notable after SCI, and both of these factors will have strong implications for oxidative stress and antioxidant capacity. A sedentary lifestyle combined with poor dietary balance could result in overabundance of glucose and fatty acid accumulation, which in turn could lead to the production of excess ROS through the mitochondrial electron transport chain. ${ }^{62}$ Indeed, several studies have shown that antioxidant capacity is dependent on the level of physical activity. Elite athletes and able-bodied adults who participate in some form of regular exercise or physical activity have higher resting levels of glutathione (one of the human body's main antioxidants), lower resting levels of glutathione disulfide (the oxidized form of glutathione) and improved antioxidant response to graded exercise tests compared with age-matched sedentary subjects. ${ }^{63,64}$ Trained athletes also show higher levels of antioxidant enzyme activity (for example, SOD, GPx) and lower levels of blood markers of oxidative stress (for example, malondialdehyde, a byproduct of lipid peroxidation) compared with sedentary controls. ${ }^{65-67}$ Similar findings have been found in tetraplegic rugby players, who show higher levels of catalase and GPx activity compared with their sedentary counterparts. ${ }^{6}$ In another study, sedentary individuals with SCI were found to have higher levels of lipid peroxides both at rest and in response to strenuous exercise compared with able-bodied individuals. ${ }^{69}$ Also, while able-bodied individuals showed an increase in NO (acting as an antioxidant) with strenuous arm cycling, individuals with SCI showed no change in NO concentration. ${ }^{69}$ Thus, existing levels of physical conditioning could have implications for the prescription of training regimens in people with SCI.

Dietary intake could also impact antioxidant capacity in people with SCI. Many nutrients derived from our diet provide an important source of antioxidants to the body and there is an enormous body of literature pointing to the association between diets rich in antioxidant-containing fruits and vegetables and the risk of chronic disease. $^{70}$ The most important diet-derived antioxidants include vitamin E, a lipid-soluble antioxidant that protects against lipid peroxidation by neutralizing ROS (including $\mathrm{O}_{2}{ }^{-} \bullet$ ) and vitamin $\mathrm{C}$, which is water-soluble and directly reacts with $\mathrm{O}_{2}{ }^{-} \bullet$ and $\mathrm{OH} \bullet$. Studies analyzing nutritional intake after SCI indicate that people with SCI tend to have less than the recommended intake of antioxidant vitamins (especially vitamins $\mathrm{C}, \mathrm{E}$ and $\mathrm{A}){ }^{71-75}$ Although most studies of nutritional status in SCI are framed with respect to risk of obesity and cardiovascular disease, ${ }^{71,73}$ dietary antioxidant capacity should also be considered in rehabilitation and exercise management following SCI.

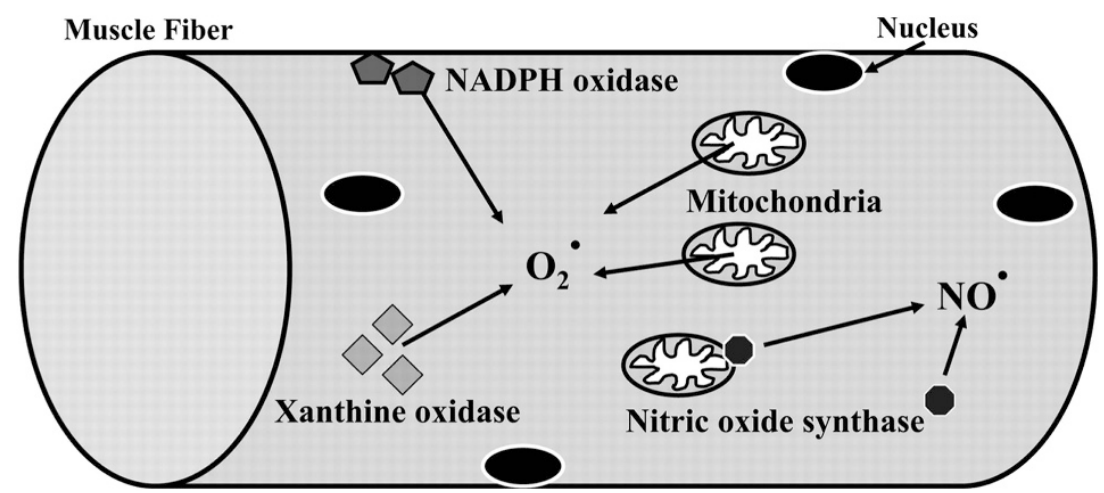

Figure 2 Oxidative stress and rehabilitation/exercise training parameters in SCl. Simplified diagram illustrating pathways capable of producing superoxide and nitric oxide in skeletal muscle during periods of disuse. Candidates for the production of reactive oxygen include NADPH oxidase, xanthine oxidase and muscle mitochondria. Nitric oxide is likely produced by skeletal muscle nitric oxide synthase. Figure from Powers et al. ${ }^{53}$ reproduced by permission of the American Physiological Association. 


\section{OXIDATIVE STRESS AND REHABILITATION IN CHRONIC SCI}

There has been increasing focus and interest on physical rehabilitation strategies that involve intensive, repetitive movements, such as functional electrical stimulation-assisted cycling, arm ergometry or BWSTT. $^{76,77}$ Such modalities are restricted not only to rehabilitation therapy but are also among the recommended activities that could be included as part of ongoing regular exercise programs for people with SCI. ${ }^{78}$ Gait rehabilitation interventions, particularly BWSTT, have arguably received the most widespread attention among SCI rehabilitation researchers, both for improving walking function, as well as its potential to confer such secondary benefits as improvements in cardiovascular health, muscle composition and metabolism, bone health and psychological well-being. ${ }^{79}$ However, beyond the general principle that training should provide intensive and repetitive practice of task-specific movements, there is little rationale for administering a particular intensity, duration or frequency of training. Indeed, it is clear that training parameters can vary widely across the literature. For BWSTT, training parameters in research studies have ranged from 2 to 5 times per week, 20-60 min per session for $2-48$ weeks; ${ }^{77}$ the number of training sessions can vary widely even within a single study. ${ }^{80,81}$ Rehabilitation researchers are still challenged to establish the optimal training parameters required to achieve functional improvements. Considerations of the potential effects of oxidative stress in SCI will be an important factor in addressing this issue.

There are indications from other studies that both the intensity of training, as well as training frequency and duration will have an impact on oxidative stress and antioxidant responses. Many forms of rehabilitation therapy, such as BWSTT or arm and leg cycling, are associated with levels of perceived exertion indicative of moderate to heavy intensity. ${ }^{6,82}$ Moreover, the additional use of electrical stimulation to enhance muscle activation will contribute to the intensity of exercise. Results from animal studies suggest that even moderate exercise intensity can trigger antioxidant responses, particularly in fast-twitch muscles. ${ }^{59}$ Similarly, malondialdehyde concentration is increased to a greater extent in fast-twitch muscles, and this increase will be greater as exercise intensity increases. ${ }^{83}$ In humans, blood markers of lipid peroxidation and antioxidant status have also been shown to be increased with increasing levels of exercise intensity (as gauged by $\% V_{2} \max$ ). ${ }^{84}$ The relationship between oxidative stress and antioxidant capacity with respect to training intensity in people with SCI remains to be elucidated.

The question of how antioxidant defense systems can tolerate higher training frequencies (for example, consecutive vs alternate days) will also be important for determining optimal rehabilitation parameters in people with SCI. Anecdotally, an increase in perceived level of exertion associated with subjective and objective measures of muscle fatigue are common the next day after walking exercise; this could be linked to oxidative stress, ${ }^{85}$ but it has never been systematically investigated in SCI. In terms of training frequency, data from able-bodied individuals suggest that changes in antioxidant level in response to exercise could depend on training status. Viguie et al. ${ }^{86}$ found that blood glutathione and ascorbate (vitamin C) levels did not differ between the first and third day of consecutive exercise in a group of healthy, recreationally active adults. Similarly, highly trained cyclists do not show cumulative effects of oxidative stress over consecutive days of exercise. ${ }^{87}$ However, a study comparing professional elite cyclists to recreational cyclists showed that increases in blood levels of antioxidant vitamins in response to exercise will vary with training status. $^{88}$ Professional cyclists significantly increased plasma ascorbic acid (vitamin C) and $\alpha$-tocopherol (vitamin E) concentrations but recreational cyclists had no change in these antioxidant vitamins after exercise. ${ }^{88}$ For people with SCI, who may already be deconditioned and have detrimental changes in muscle morphology and function, better understanding of how the frequency of training impacts oxidative stress responses is required, particularly in determining the initial dosage of rehabilitation programs.

Nevertheless, we should be able to reasonably expect that with ongoing training, antioxidant defense systems can adapt and improve. In sedentary, able-bodied individuals, a 6-week exercise program resulted in a significant increase in resting glutathione and decrease in glutathione disulfide levels compared with a control (no exercise) group. ${ }^{89}$ Similar findings of decreased oxidative stress, accompanied by improvements in aerobic fitness with long-term (up to 12 months) exercise training were found among a group of previously sedentary older adults. ${ }^{90,91}$ However, improvements in antioxidant capacity are also readily reversed by detraining (e.g. if exercise is ceased for 4 months),${ }^{90}$ illustrating the fluid nature of the oxidative-antioxidant balance. Data from tetraplegic rugby players indicate that long-term training (i.e. average of 7 years of rugby experience) can afford beneficial adaptations in antioxidant systems (such as increased resting levels of antioxidant enzymes), similar to trained able-bodied athletes. ${ }^{68}$ In contrast, individuals with chronic SCI who underwent a shorter-term exercise program (30-min functional electrical stimulation cycling, $2-3 \times$ per week for 8 weeks) had no change in resting or postexercise levels of malondialdehyde, SOD or GPx. ${ }^{92}$ More studies will be needed to understand the adaptive capacity and time course of adaptation of the oxidative stress system following SCI to determine the optimum progression of training parameters.

\section{CONCLUSIONS}

Rehabilitation and exercise training are important for maintaining lifelong health and fitness in people with SCI. Although there is still much to be understood for determining optimal training parameters for rehabilitation and exercise therapies, it is encouraging that the recently released evidence-based guidelines for general physical activity and exercise for people with $\mathrm{SCI}^{78}$ enforces the notion of gradually building up exercise intensity. However, for rehabilitation strategies promoting neural recovery, the intensity, frequency and duration of the exercise has seemed to rely mainly on the adage of 'the more the better', but we have little understanding of the potential confounding effects of excessive free radical production if interventions are undertaken too strenuously, particularly during the initial stages of rehabilitation. People with SCI already experience changes in muscle morphology along with changes in lifestyle that could predispose them to greater risk of oxidative stress and reduced antioxidative capacity. Indeed, there is evidence that even as early as 1 month postinjury, individuals with SCI have lower levels of antioxidant markers and higher levels of urine markers of oxidative stress compared with controls. ${ }^{93}$ Certainly the balance between optimizing neuromotor recovery, the potential damaging effects of excessive free radical production with training and the importance of incorporating appropriate nutritional guidelines will all be needed to be taken into consideration as rehabilitation research continues to advance our understanding of the optimal prescription of training interventions.

\section{DATA ARCHIVING}

There were no data to deposit.

\section{CONFLICT OF INTEREST}

The authors declare no conflict of interest. 


\section{ACKNOWLEDGEMENTS}

We thank Cheryl Niamath for the illustrations in Figure 1. This work was supported by the King Saud University-International Twinning Program. TL was supported by a New Investigator Award from the Canadian Institutes of Health Research.

1 Wyndaele M, Wyndaele JJ. Incidence, prevalence and epidemiology of spinal cord injury: what learns a worldwide literature survey? Spinal Cord 2006; 44: 523-529.

2 Pentland W, Harvey AS, Smith T, Walker J. The impact of spinal cord injury on men's time use. Spinal Cord 1999; 37: 786-792.

3 Garshick E, Kelley A, Cohen SA, Garrison A, Tun CG, Gagnon D et al. A prospective assessment of mortality in chronic spinal cord injury. Spinal Cord 2005; 43: 408-416.

4 Noreau L, Shephard RJ. Spinal cord injury, exercise and quality of life. Sports Med 1995; 20: 226-250

5 Ashe MC, Craven BC, Krassioukov A, Eng JJ. Bone health following spinal cord injury. In: Eng JJ, Teasell RW, Miller WC, Wolfe DL, Townson AF and Aubut J et al. (eds) Spinal Cord Injury Rehabilitation Evidence. ICORD: Vancouver, BC, 2006.

6 Hicks AL, Martin KA, Ditor DS, Latimer AE, Craven C, Bugaresti J et al. Long-term exercise training in persons with spinal cord injury: effects on strength, arm ergometry performance and psychological well-being. Spinal Cord 2003; 41: 34-43.

7 Harkema SJ, Ferreira CK, van den Brand RJ, Krassioukov AV. Improvements in orthostatic instability with stand locomotor training in individuals with spinal cord injury. J Neurotrauma 2008; 25: 1467-1475.

8 Duran FS, Lugo L, Ramirez L, Eusse E. Effects of an exercise program on the rehabilitation of patients with spinal cord injury. Arch Phys Med Rehabil 2001; 82 1349-1354.

9 Hicks AL, Martin Ginis KA, Pelletier CA, Ditor DS, Foulon B, Wolfe DL. The effects of exercise training on physical capacity, strength, body composition and functional performance among adults with spinal cord injury: a systematic review. Spinal Cord 2011; 49: 1103-1127.

10 Edgerton VR, Roy RR. Activity-dependent plasticity of spinal locomotion: implications for sensory processing. Exerc Sport Sci Rev 2009; 37: 171-178.

11 Davies KJ, Quintanilha AT, Brooks GA, Packer L. Free radicals and tissue damage produced by exercise. Biochem Biophys Res Commun 1982; 107: 1198-1205.

12 Jia Z, Zhu H, Li J, Wang X, Misra H, Li Y. Oxidative stress in spinal cord injury and antioxidant-based intervention. Spinal Cord 2012; 50: 264-274.

13 Dobkin $\mathrm{BH}$. Fatigue versus activity-dependent fatigability in patients with central or peripheral motor impairments. Neurorehab Neural Repair 2008; 22: 105-110.

14 Haisma JA, van der Woude LH, Stam HJ, Bergen MP, Sluis TA, Bussmann JB. Physical capacity in wheelchair-dependent persons with a spinal cord injury: a critical review of the literature. Spinal Cord 2006; 44: 642-652.

15 Qin W, Bauman WA, Cardozo C. Bone and muscle loss after spinal cord injury: organ interactions. Ann NY Acad Sci 2010; 1211: 66-84

16 Chance B, Sies H, Boveris A. Hydroperoxide metabolism in mammalian organs. Physio Rev 1979; 59: 527-605

17 Finaud J, Lac G, Filaire E. Oxidative stress: relationship with exercise and training. Sports Med 2006; 36: 327-358.

18 St-Pierre J, Buckingham JA, Roebuck SJ, Brand MD. Topology of superoxide production from different sites in the mitochondrial electron transport chain. J Biol Chem 2002; 277: 44784-44790.

19 Powers SK, Jackson MJ. Exercise-induced oxidative stress: cellular mechanisms and impact on muscle force production. Physiol Rev 2008; 88: 1243-1276.

20 Jackson MJ. Free radicals generated by contracting muscle: by-products of metabolism or key regulators of muscle function? Free Radic Biol Med 2008; 44: 132-141.

21 Cherednichenko G, Zima AV, Feng W, Schaefer S, Blatter LA, Pessah IN. NADH oxidase activity of rat cardiac sarcoplasmic reticulum regulates calcium-induced calcium release. Circ Res 2004; 94: 478-486.

22 Hidalgo C, Sanchez G, Barrientos G, Aracena-Parks P. A transverse tubule NADPH oxidase activity stimulates calcium release from isolated triads via ryanodine receptor type 1S-glutathionylation. J Biol Chem 2006; 281: 26473-26482.

23 Reid MB. Nitric oxide, reactive oxygen species, and skeletal muscle contraction. Med Sci Sports Exerc 2001; 33: 371-376

24 Pani G, Colavitti R, Bedogni B, Anzevino R, Borrello S, Galeotti T. A redox signaling mechanism for density-dependent inhibition of cell growth. J Biol Chem 2000; 275: 38891-38899.

25 Stadtman ER. Protein oxidation and aging. Free Radic Res 2006; 40: 1250-1258.

26 Cooke MS, Evans MD, Dizdaroglu M, Lunec J. Oxidative DNA damage: mechanisms, mutation, and disease. FASEB J 2003; 17: 1195-1214.

27 Halliwell B, Chirico S. Lipid peroxidation: its mechanism, measurement, and significance. Am J Clin Nutr 1993. 57 (Suppl), 715S-724S. discussion 724S-725S.

28 Droge W. Free radicals in the physiological control of cell function. Physiol Rev 2002; 82: 47-95.

29 Halliwell B, Gutteridge J. Free Radicals in Biology and Medicine. Oxford University Press: Oxford, 1999.

30 Sies H. Oxidative stress: oxidants and antioxidants. Exp Physiol 1997; 82: 291-295.

31 Halliwell B. Antioxidant defence mechanisms: from the beginning to the end (of the beginning). Free Radic Res 1999; 31: 261-272.

32 Powers SK, DeRuisseau KC, Quindry J, Hamilton KL. Dietary antioxidants and exercise. J Sports Sci 2004; 22: 81-94.
33 Reid MB, Khawli FA, Moody MR. Reactive oxygen in skeletal muscle. III. Contractility of unfatigued muscle. J Appl Physiol 1993; 75: 1081-1087.

34 Reid MB, Moody MR. Dimethyl sulfoxide depresses skeletal muscle contractility. J App/ Physiol 1994; 76: 2186-2190.

35 Balon TW, Nadler JL. Nitric-oxide release is present from incubated skeletal-muscle preparations. J Appl Physiol 1994; 77: 2519-2521.

36 Roberts CK, Barnard RJ, Jasman A, Balon TW. Acute exercise increases nitric oxide synthase activity in skeletal muscle. Am J Physiol 1999; 277 (Part 1), E390-E394.

37 Reid MB, Kobzik L, Bredt DS, Stamler JS. Nitric oxide modulates excitation-contraction coupling in the diaphragm. Comp Biochem Physiol A 1998; 119: 211-218.

38 Kobzik L, Reid MB, Bredt DS, Stamler JS. Nitric oxide in skeletal muscle. Nature 1994: 372: 546-548.

39 Stamler JS, Meissner G. Physiology of nitric oxide in skeletal muscle. Physiol Rev 2001; 81: 209-237.

40 Reid MB. Role of nitric oxide in skeletal muscle: synthesis, distribution and functional importance. Acta Physiol Scand 1998; 162: 401-409.

41 Jackson MJ, Pye D, Palomero J. The production of reactive oxygen and nitrogen species by skeletal muscle. J Appl Physiol 2007; 102: 1664-1670.

42 Biering-Sorensen B, Kristensen IB, Kjaer M, Biering-Sorensen F. Muscle after spinal cord injury. Musc Nerve 2009; 40: 499-519.

43 Nash MS. Exercise as a health-promoting activity following spinal cord injury. J Neurol Phys Ther 2005; 29: 87-103. 106.

44 Castro MJ, Apple DF Jr, Hillegass EA, Dudley GA. Influence of complete spinal cord injury on skeletal muscle cross-sectional area within the first 6 months of injury. Eur $J$ Appl Physiol Occup Physiol 1999; 80: 373-378.

45 Castro MJ, Apple DF Jr, Staron RS, Campos GE, Dudley GA. Influence of complete spinal cord injury on skeletal muscle within 6 mo of injury. J Appl Physiol 1999; 86: 350-358.

46 Kondo $\mathrm{H}$, Miura M, Itokawa Y. Oxidative stress in skeletal muscle atrophied by immobilization. Acta Physiol Scand 1991; 142: 527-528.

47 Dalla Libera L, Ravara B, Gobbo V, Tarricone E, Vitadello M, Biolo G et al. A transient antioxidant stress response accompanies the onset of disuse atrophy in human skeletal muscle. J Appl Physiol 2009; 107: 549-557.

48 Powers SK, Wiggs MP, Duarte JA, Zergeroglu AM, Demirel HA. Mitochondrial signaling contributes to disuse muscle atrophy. Am J Physiol Endocrinol Metab 2012; 303. E31-E39.

49 Min K, Smuder AJ, Kwon OS, Kavazis AN, Szeto HH, Powers SK. Mitochondrialtargeted antioxidants protect skeletal muscle against immobilization-induced muscle atrophy. J App/ Physiol 2011; 111: 1459-1466.

50 Powers SK, Hudson MB, Nelson WB, Talbert EE, Min K, Szeto HH et al. Mitochondriatargeted antioxidants protect against mechanical ventilation-induced diaphragm weakness. Crit Care Med 2011; 39: 1749-1759.

51 Kondo H, Miura M, Nakagaki I, Sasaki S, Itokawa Y. Trace element movement and oxidative stress in skeletal muscle atrophied by immobilization. Am J Physiol 1992; 262 (Part 1), E583-E590.

52 Kondo H, Nakagaki I, Sasaki S, Hori S, Itokawa Y. Mechanism of oxidative stress in skeletal-muscle atrophied by immobilization. Am J Physiol 1993. 265: E839-E844.

53 Powers SK, Kavazis AN, McClung JM. Oxidative stress and disuse muscle atrophy. J Appl Physiol 2007; 102: 2389-2397.

54 Round JM, Barr FM, Moffat B, Jones DA. Fibre areas and histochemical fibre types in the quadriceps muscle of paraplegic subjects. J Neurol Sci 1993; 116: 207-211.

55 Grimby G, Broberg C, Krotkiewska I, Krotkiewski M. Muscle fiber composition in patients with traumatic cord lesion. Scand J Rehabil Med 1976; 8: 37-42.

56 Burnham R, Martin T, Stein R, Bell G, MacLean I, Steadward R. Skeletal muscle fibre type transformation following spinal cord injury. Spinal Cord 1997; 35: 86-91.

57 Talmadge RJ, Castro MJ, Apple DF Jr, Dudley GA. Phenotypic adaptations in human muscle fibers 6 and 24 wk after spinal cord injury. J Appl Physiol 2002: 92: 147-154.

58 Anderson EJ, Neufer PD. Type II skeletal myofibers possess unique properties that potentiate mitochondrial $\mathrm{H}(2) \mathrm{O}(2)$ generation. Am J Physiol Cell Physiol 2006; 290: C844-C851.

$59 \mathrm{Ji}$ LL, Fu R, Mitchell EW. Glutathione and antioxidant enzymes in skeletal muscle: effects of fiber type and exercise intensity. J App/ Physiol 1992; 73: 1854-1859.

60 Powers SK, Criswell D, Lawler J, Ji LL, Martin D, Herb RA et al. Influence of exercise and fiber type on antioxidant enzyme activity in rat skeletal muscle. Am J Physiol 1994; 266 (Pt 2), R375-R380

61 Lawler JM, Powers SK, Visser T, Van Dijk H, Kordus MJ, Ji LL. Acute exercise and skeletal muscle antioxidant and metabolic enzymes: effects of fiber type and age. Am J Physiol 1993; 265 (Pt 2), R1344-R1350.

62 Brownlee M. Biochemistry and molecular cell biology of diabetic complications. Nature 2001; 414: 813-820.

63 Douris PC, Elokda AS, Handrakis JP, Principal S, Rondo E, Bovell J et al. Martial art training enhances the glutathione antioxidant system in middle-aged adults. J Strength Cond Res 2009; 23: 1518-1523.

64 Subudhi AW, Min-Xin F, Strothkamp KG, Murray DM. Effect of graded exercise on blood glutathione status in trained and untrained humans. Int Sports J 2003; 7: 82-90.

65 Cazzola R, Russo-Volpe S, Cervato G, Cestaro B. Biochemical assessments of oxidative stress, erythrocyte membrane fluidity and antioxidant status in professional soccer players and sedentary controls. Eur J Clin Invest 2003; 33: 924-930.

$66 \mathrm{Knez} \mathrm{WL}$, Jenkins DG, Coombes JS. Oxidative stress in half and full Ironman triathletes. Med Sci Sports Exerc 2007; 39: 283-288. 
67 Teixeira V, Valente H, Casal S, Marques F, Moreira P. Antioxidant status, oxidative stress, and damage in elite trained kayakers and canoeists and sedentary controls. Int Sport Nutr Exerc Metab 2009; 19: 443-456.

68 Hubner-Wozniak E, Morgulec-Adamowicz N, Malara M, Lewandowski P, OkeckaSzymanska J. Effect of rugby training on blood antioxidant defenses in able-bodied and spinal cord injured players. Spinal Cord 2012; 50: 253-256.

69 Wang JS, Yang CF, Wong MK, Chow SE, Chen JK. Effect of strenuous arm exercise on oxidized-LDL-potentiated platelet activation in individuals with spinal cord injury. Thromb Haemost 2000; 84: 118-123.

70 Halliwell B. Establishing the significance and optimal intake of dietary antioxidants: the biomarker concept. Nutr Rev 1999; 57: 104-113.

71 Groah SL, Nash MS, Ljungberg IH, Libin A, Hamm LF, Ward E et al. Nutrient intake and body habitus after spinal cord injury: an analysis by sex and level of injury. J Spinal Cord Med 2009; 32: 25-33.

72 Levine AM, Nash MS, Green BA, Shea JD, Aronica MJ. An examination of dietary intakes and nutritional status of chronic healthy spinal cord injured individuals. Paraplegia 1992; 30: 880-889.

73 Tomey KM, Chen DM, Wang X, Braunschweig CL. Dietary intake and nutritional status of urban community-dwelling men with paraplegia. Arch Phys Med Rehabil 2005; 86: 664-671.

74 Walters JL, Buchholz AC, Martin Ginis KA. Evidence of dietary inadequacy in adults with chronic spinal cord injury. Spinal Cord 2009; 47: 318-322.

75 Perret C, Stoffel-Kurt N. Comparison of nutritional intake between individuals with acute and chronic spinal cord injury. J Spinal Cord Med 2011; 34: 569-575.

76 Jacobs PL, Nash MS. Exercise recommendations for individuals with spinal cord injury. Sports Med 2004; 34: 727-751.

77 Wessels M, Lucas C, Eriks I, de Groot S. Body weight-supported gait training for restoration of walking in people with an incomplete spinal cord injury: a systematic review. J Rehabil Med 2010; 42: 513-519.

78 Martin Ginis KA, Hicks AL, Latimer AE, Warburton DE, Bourne C, Ditor DS et al. The development of evidence-informed physical activity guidelines for adults with spinal cord injury. Spinal Cord 2011; 49: 1088-1096.

79 Hicks A, Ginis KA. Treadmill training after spinal cord injury: it's not just about the walking. J Rehabil Res Dev 2008; 45: 241-248.

80 Harkema SJ, Schmidt-Read M, Lorenz DJ, Edgerton VR, Behrman AL. Balance and ambulation improvements in individuals with chronic incomplete spinal cord injury using locomotor training-based rehabilitation. Arch Phys Med Rehabil 2012; 93: 1508-1517.
81 Harkema SJ, Hillyer J, Schmidt-Read M, Ardolino E, Sisto SA, Behrman AL. Locomotor training: as a treatment of spinal cord injury and in the progression of neurologic rehabilitation. Arch Phys Med Rehabil 2012; 93: 1588-1597.

82 Lewis JE, Nash MS, Hamm LF, Martins SC, Groah SL. The relationship between perceived exertion and physiologic indicators of stress during graded arm exercise in persons with spinal cord injuries. Arch Phys Med Rehabil 2007; 88: 1205-1211.

83 Alessio HM, Goldfarb AH, Cutler RG. MDA content increases in fast- and slow-twitch skeletal muscle with intensity of exercise in a rat. Am J Physiol 1988; 255 (Pt 1) c874-C877.

84 Toshinai K, Ohno H, Bae SY, Iwashita T, Koseki S, Haga S. Effect of different intensity and duration of exercise with the same total oxygen uptake on lipid peroxidation and antioxidant enzyme levels in human plasma. Adv Exerc Sports Physiol 1998; 4 65-70.

85 Tiidus PM. Radical species in inflammation and overtraining. Can J Physiol Pharmacol 1998; 76: 533-538.

86 Viguie CA, Frei B, Shigenaga MK, Ames BN, Packer L, Brooks GA. Antioxidant status and indexes of oxidative stress during consecutive days of exercise. J Appl Physio 1993; 75: 566-572.

87 Shing CM, Peake JM, Ahern SM, Strobel NA, Wilson G, Jenkins DG et al. The effect of consecutive days of exercise on markers of oxidative stress. Appl Physiol Nutr Metab 2007; 32: 677-685.

88 Aguilo A, Tauler P, Pilar Guix M, Villa G, Cordova A, Tur JA et al. Effect of exercise intensity and training on antioxidants and cholesterol profile in cyclists. J Nutr Biochem 2003; 14: 319-325.

89 Elokda AS, Nielsen DH. Effects of exercise training on the glutathione antioxidant system. Eur J Cardiovasc Prev Rehabil 2007; 14: 630-637.

90 Fatouros IG, Jamurtas AZ, Villiotou V, Pouliopoulou S, Fotinakis P, Taxildaris K et al. Oxidative stress responses in older men during endurance training and detraining. Med Sci Sports Exerc 2004; 36: 2065-2072.

91 Campbell PT, Gross MD, Potter JD, Schmitz KH, Duggan C, McTiernan A et al. Effect of exercise on oxidative stress: a 12-month randomized, controlled trial. Med Sci Sports Exerc 2010; 42: 1448-1453.

92 van Duijnhoven N, Hesse E, Janssen T, Wodzig W, Scheffer P, Hopman M. Impact of exercise training on oxidative stress in individuals with a spinal cord injury. Eur J Appl Physiol 2010; 109: 1059-1066.

93 Bastani NE, Kostovski E, Sakhi AK, Karlsen A, Carlsen MH, Hjeltnes N et al. Reduced antioxidant defense and increased oxidative stress in spinal cord injured patients. Arch Phys Med Rehabil 2012; 93: 2223-2228. 